\title{
Fabrication and Characterization of Freestanding NiTi Based Thin Film Materials for Shape Memory Micro-actuator Applications
}

\author{
Christoph Bechtold $^{1}\left(\right.$ Christoph $^{-}$Chluba $^{1} \cdot$ Christiane Zamponi $^{1,2}$. \\ Eckhard Quandt ${ }^{2} \cdot$ Rodrigo Lima de Miranda ${ }^{1}$
}

Published online: 5 November 2019

(C) ASM International 2019

\begin{abstract}
Thin film shape memory actuators fabricated by micro-system technology processes are of particular interest in micro-actuator applications due to their high work output, large displacements, and a comparably easy and compact system setup. Micro-system technology processes allow to deposit and structure ultra-precise parts from a wide range of alloys, among them alloys that are difficult to process with conventional fabrication techniques. However, sputtered NiTi based thin films are seldom deposited with thicknesses $>10 \mu \mathrm{m}$, which limits their range of application as well as makes the handling of freestanding films difficult. In this work, freestanding NiTi, NiTiCu, and NiTiHf shape memory structures were fabricated by means of sputtering, lithography, and wet etching, with a process that allows for thicknesses up to $80 \mu \mathrm{m}$. Their high cycle actuation behavior and microstructure were characterized. $\mathrm{NiTiCu}$ actuators show an excellent cyclic stability, resulting in high fatigue lives of $>10^{8}$ cycles at $1.5 \%$ strain, even for stresses as high as $550 \mathrm{MPa}$. A distinct martensite/austenite interface is observed during transformation, in contrast to NiTi exhibiting a rather homogeneous transformation during heating and cooling throughout the sample volume. Sputtered NiTiHf actuators
\end{abstract}

This article is an invited submission to Shape Memory and Superelasticity selected from presentations at the Shape Memory and Superelastic Technology Conference and Exposition (SMST2019) held May 13-17, 2019 at The Bodensee Forum in Konstanz, Germany, and has been expanded from the original presentation.

Christoph Bechtold

bechtold@acquandas.com

Acquandas GmbH, Kaiserstrasse 2, 24143 Kiel, Germany

2 Inorganic Functional Materials, Christian AlbrechtsUniversität Zu Kiel, Kaiserstrasse 2, 24143 Kiel, Germany tested in air can reach fatigue lives as high as $1.5 \times 10^{6}$ cycles at $1 \%$ strain.

Keywords NiTi $\cdot \mathrm{NiTiHf} \cdot$ Mechanical behavior - Shape memory films · Thermal cycling

\section{Introduction}

Sputtering is currently the method of choice for the fabrication of NiTi based thin films. Sputtered NiTi alloys have been investigated for more than 25 years [1-6], and a wide range of binary, ternary, and quaternary compositions has been fabricated and characterized. Using a micro-system technology process developed by 2013 [7], freestanding films up to $80 \mu \mathrm{m}$ in thickness, high geometrical precision and material purity can be deposited by DC magnetron sputtering from unheated NiTiX alloy targets. This opens up new possibilities in designing next generations of miniaturized Nitinol devices, in particular for medical but also for other industrial applications [8-10]. The versatility of micro-system technology processes further allows for integrating additional features to the Nitinol structures, such as X-ray markers [11], micro-electrodes [12], and other sensors.

Another benefit of the micro-system technology approach is that samples from different alloys can be fabricated and structured with almost identical process parameters, without the need of cold or hot work or forging which often lead to difficulties in the processing of brittle materials. Thus, beside extensive work on binary NiTi [13-18], sputtered films from NiTiCu [19-22], NiTiHf [23-25], NiTiPd [5, 26-30], and NiTiZr [23, 31] have been investigated. Like NiTiCu bulk material, sputtered $\mathrm{NiTiCu}$ films reveal excellent functional stability during cyclic 
loading. This functional stability has its origin in the geometric compatibility of the austenitic and martensitic phases, indicated by an eigenvalue of the transformation matrix close to 1 [32]. This allows for a phase reversibility without significant permanent deformation, and is true both for the temperature-induced (shape memory) and the stress-induced transformation (superelasticity, at higher temperatures) [33, 34]. For quaternary NiTiCuCo films, where Co reduces the transformation temperatures below RT, ultra-low fatigue has been reported during superelastic cycling up to $1 \times 10^{7}$ cycles $[35,36]$. However, the increase in cyclic stability comes with a decrease in reversible strain, which is in the order of $1.5 \%$ for $\mathrm{NiTiCu}$ thin films. Tremendous actuation strains of up to $15 \%$ have been observed locally in single crystals of the high temperature shape memory alloy NiTiHf [37, 38], another promising shape memory actuator material. Depending on composition, transformation temperature can be adjusted within a wide range up to $500{ }^{\circ} \mathrm{C}$, but the comparably large hysteresis width might be detrimental for their usage in specific applications.

Shape memory actuators films are mainly employed in micro-valves, -pumps, and -grippers [39-48], where life time and cyclic repeatability of the actuator performance is pivotal. However, the high cycle fatigue behavior of sputtered thin films, which is greatly determined by processing parameters, has been addressed only rarely. The aim of this study is to characterize freestanding, sputtered $\mathrm{NiTiCu}$ and NiTiHf thin films for high cycle applications.

\section{Methods and Fabrication}

The basic processing sequence is described by Miranda et al. [7]. We pre-structured a sacrificial layer system on non-oxidized $4^{\prime \prime}$ silicon wafers lithographically by spin coating a positive photoresist, followed by UV exposure on a Karl Suess mask aligner MJB4 in hard contact mode, development, and wet chemical etching. NiTiX is deposited from $4^{\prime \prime}$ alloy targets of corresponding composition with an Alcatel 450 magnetron sputtering system up to a thickness of 20-25 $\mu \mathrm{m}$. After release from the substrate the freestanding films are annealed in a high vacuum chamber in order to avoid oxidation during the annealing process, Fig. 1. During heat treatment, the amorphous NiTiX structure is crystallized to obtain shape memory behavior. Heat treatment was carried out by means of a halogen-lamp driven rapid thermal annealing system (Createc Fischer RTA-6 SY09) and an electrochemical finish was applied to smoothen sample edges.

Transformation temperatures were determined by DSC (PerkinElmer Pyris 1) at a temperature sweep rate of $10 \mathrm{~K} /$ min, with sample masses $<5 \mathrm{mg}$. Scanning transmission electron microscopy (STEM) was used to obtain further information about the microstructures; serving this purpose cross sections of the foils were prepared by focused ion beam (FIB) using a Helios NanoLab 600 (FEI). STEM images were captured using bright field (BF) and high angular annular dark field (HAADF) detectors.

Optical surface investigations were performed with a Zeiss Axiomat polarization microscope, an effective method which exploits the difference of austenite and martensite surface roughness to visualize transformation characteristics, i.e., interfaces or continuous roughness changes [49]. Samples were mounted in a self-built micro tensile holder consisting of an actuator (Pi M226-26S) and a load cell enabling the application of a constant stress level during direct heating of samples between 0.1 and $0.6 \mathrm{~A}$ (sample width $500 \mu \mathrm{m}$ ). 100 thermal cycles were recorded.

To assess lifetime and cyclic stability of the actuation behavior, a custom high cycle fatigue test rig was developed, see Fig. 2. Samples are clamped between an upper and lower stainless steel clamping jaw with electrical contacts. The upper clamping jaw is connected to a movable axis holding a ferromagnetic steel plate for position detection. The axis is guided between two low friction high precision brass bearings and connected to a spring with low spring constant. Thus a constant pre-load can be applied via the spring using dead weights. The test rig contains seven individual test stands which can be operated individually. An Arduino microcontroller is used to switch off the applied voltage of $10 \mathrm{~V}$ used for actuation once the samples reaches a predefined target strain. A LabView program is used for data analysis and communication of control parameters to the Arduino. The test rig is within a temperature controlled environment, samples can be actuated either in a silicone oil bath $\left(11^{\circ} \mathrm{C} \pm 0.2 \mathrm{~K}\right)$ or in air $\left(11^{\circ} \mathrm{C} \pm 1.5 \mathrm{~K}\right)$.

The procedure for actuation tests is as follows: (1) mounting the sample; (2) applying a pre-load, up to $10 \mathrm{~N}$ at RT (leading to martensitic detwinning); (3) mounting the sample holder in tempered $\mathrm{Si}$-oil bath or in temperature chamber; (4) applying a rectangular signal (up to $10 \mathrm{~V}$ ) until target strain $(0.5 \%, 1.0 \%, 1.5 \%$ etc.) is reached; (5) Timeout if strain is not reached, typically $\sim 60-80 \mathrm{~ms}$; (6) cooling, typically $\sim 200-250 \mathrm{~ms}$; and (7) cycling of steps 4-6 until sample breakage or test run out. The described procedure is thus not in accordance with ASTM E3097-17 which requires a pre-heating/cooling cycling and applying the pre-load in the austenitic/heated state [50]. However, above described procedure is commonly used in microactuator applications because of lower energy consumption and ease of use. 


\section{Results and Discussion}

\section{NiTi/NiTiCu}

NiTiCu samples of $22 \mu \mathrm{m}$ thickness and $800 \mu \mathrm{m}$ width (Fig. 1) have been tested in the high cycle fatigue test rig in silicone oil at different pre-loads ranging from 250 to $550 \mathrm{MPa}$, and different strains between 1.0 and $1.5 \%$, with a cycling frequency of $4 \mathrm{~Hz}$. A total of 15 samples were tested, no breakages were observed (Fig. 2). Figure 3a shows the repeatability of the actuation cycles; both for adjacent cycles as well as the comparison to $10^{7}$ cycles where a slight remnant offset of $0.1 \%$ strain is observed. Figure $3 \mathrm{a}$ is shown exemplary for $440 \mathrm{MPa}$ pre-load. Figure $3 \mathrm{~b}$ gives an overview of parameter sets and samples tested. All samples reached the $10^{7}$ cycle test run out, and three samples were further tested to $10^{8}$ cycles within a test duration of 10 months. Equally, no breakages were observed. No surface oxidation occurs during thermal cycling due to the rather low $A_{\mathrm{f}}$ temperature of $\mathrm{NiTiCu}$, the avoidance of overheating through the Arduino control program and the silicone oil medium. Figure 3 demonstrates the excellent cyclic behavior of NiTiCu thin films, as well as an excellent fatigue life that fulfills requirement for many actuator applications on the market.

The stability of the functional behavior correlates with a good transformation reversibility caused by the crystallographic compatibility between the martensitic and austenitic phase [32]. This also results in a small thermal hysteresis, which was confirmed by stress-free DSC measurements. DSC data for the three thin film materials

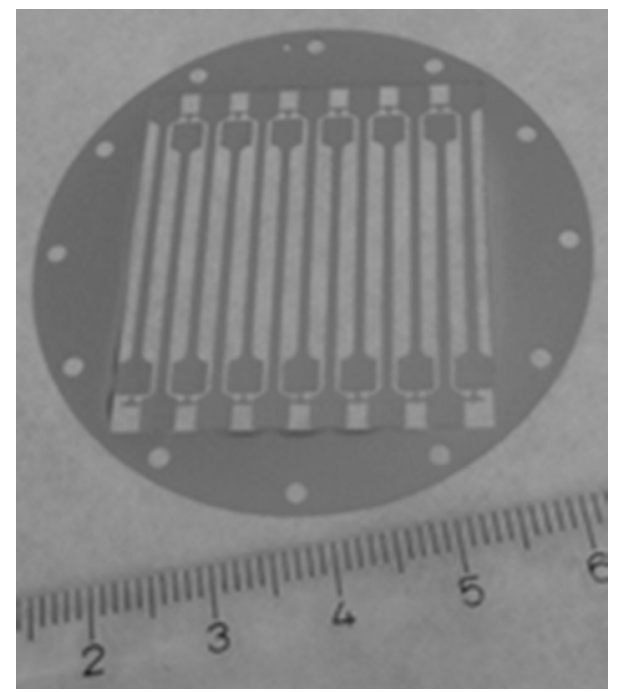

Fig. 1 Typical sample geometries used for high cycle fatigue testing, with a low surface roughness of the highly reflective metallic surface of a few tens of $\mathrm{nm}$. Cross section of the parallel length was $800 \mu \mathrm{m}$ $\times 22 \mu \mathrm{m}$ investigated in this study are shown in Table 1 , where $\mathrm{NiTiCu}$ reveals a typical hysteresis width $\left(A_{\mathrm{f}}-M_{\mathrm{f}}\right)$ of $19 \mathrm{~K}$.

The transformation in NiTiCu during actuation at a constant load is characterized by a distinct interface between the martensitic and the austenitic phase. Optical polarization microscopy reveals the interface with an angle of $53^{\circ}$ to the sample edge, Fig. 4a The growth of one phase on the expense of the other has been extensively investigated in particular for the stress-induced martensitic transformation in $\mathrm{NiTi}$, where the formation and propagation of Lüders-like transformation bands results in typical peaks/valleys in the superelastic stress-strain curve, and interfaces show a similar angle towards stress direction [51-53]. After 100 thermal cycles, the NiTiCu film reveals the same transformation characteristics, with the distinct interface still being clearly visible (Fig. 4b). In addition the comparison of the austenite surface roughness during the initial heating cycles and cycle 100 reveals no significant change, Fig. 5 (top row). This has also relevant implications on the fatigue life of the material, since a smooth surface confines stress concentrations and limits crack initiation, which originate at the surface. In contrast, the surface roughness of binary NiTi actuators clearly increases with cycling, Fig. 5 (bottom row), although a quantitative in-situ analysis was not performed in this study. Furthermore, a distinct interface between a martensitic and an austenitic phase was not observed, but a continuous increase/decrease of the surface roughness during the actuation cycle combined with a rather homogeneous global strain. Localized strains or transformation bands were equally not observed by DIC for the sputtered NiTi films.

The sputtered NiTiCu films show an average grain size of $\sim 600 \mathrm{~nm}$, with large $\mathrm{Ti}_{2} \mathrm{Ni}$ precipitates at the grain boundaries $(\sim 300 \mathrm{~nm})$ and fine globular, intra-granular precipitates of $\sim 50 \mathrm{~nm}$ in size. Grain size and precipitates have a significant influence on the martensitic transformation since they affect the formation and movement of phase boundaries within the grains, and thus important transformation characteristics such as transformation temperatures [54-57]. Also, for materials with ultra-fine grained or nanocrystalline microstructures a hardening effect is observed that reduces dislocation mobility and nucleation [58] which increases functional cyclic stability. Microstructure was characterized by metallurgical analysis and STEM/TEM imaging of samples prepared by FIB, see Fig. 6, before and after cycling. After $50 \mathrm{k}$ thermal cycles, the microstructure of the NiTiCu actuators reveals no significant changes. The microstructure of sputtered Ti-rich $\mathrm{NiTi}$ actuators crystallized by rapid thermal annealing shows typical grain sizes of a few $\mu \mathrm{m}$ and below, slightly higher compared to sputtered $\mathrm{NiTiCu}$ samples. TEM investigations show a finely twinned martensitic structure within certain grains, Fig. 7 . The presence of $\mathrm{Ti}_{2} \mathrm{Ni}$ 

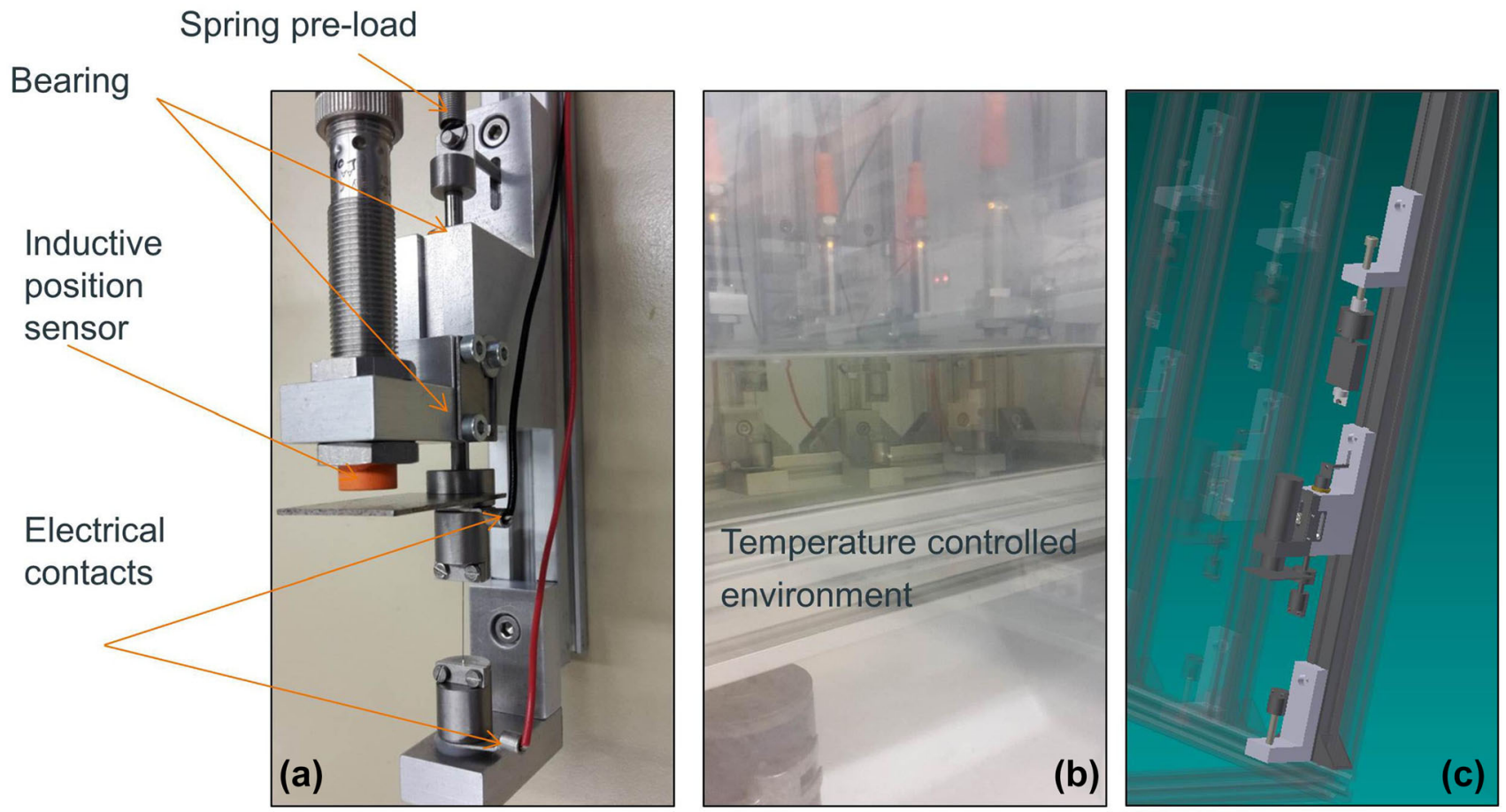

Fig. 2 Experimental setup for high cycle fatigue testing of thin film actuators. a sample mount with electrical contacts for direct heating, ferromagnetic plate for inductive position detection and spring pre- load; b Setup placed in tempered silicone oil bath with magnetic stirring; c CAD model
Fig. 3 a Sputtered NiTiCu film under actuation: exemplary measurement data for $1.5 \%$ strain at $440 \mathrm{MPa}$ spring preload and $225 \mathrm{~ms}$ cooling time. Data are shown for initial thermal cycles and cycles $10^{7}$. b High cycle fatigue test for NiTiCu films with $10^{7}$ cycles run out, three samples were tested to $10^{8}$ cycles. No breakages were observed
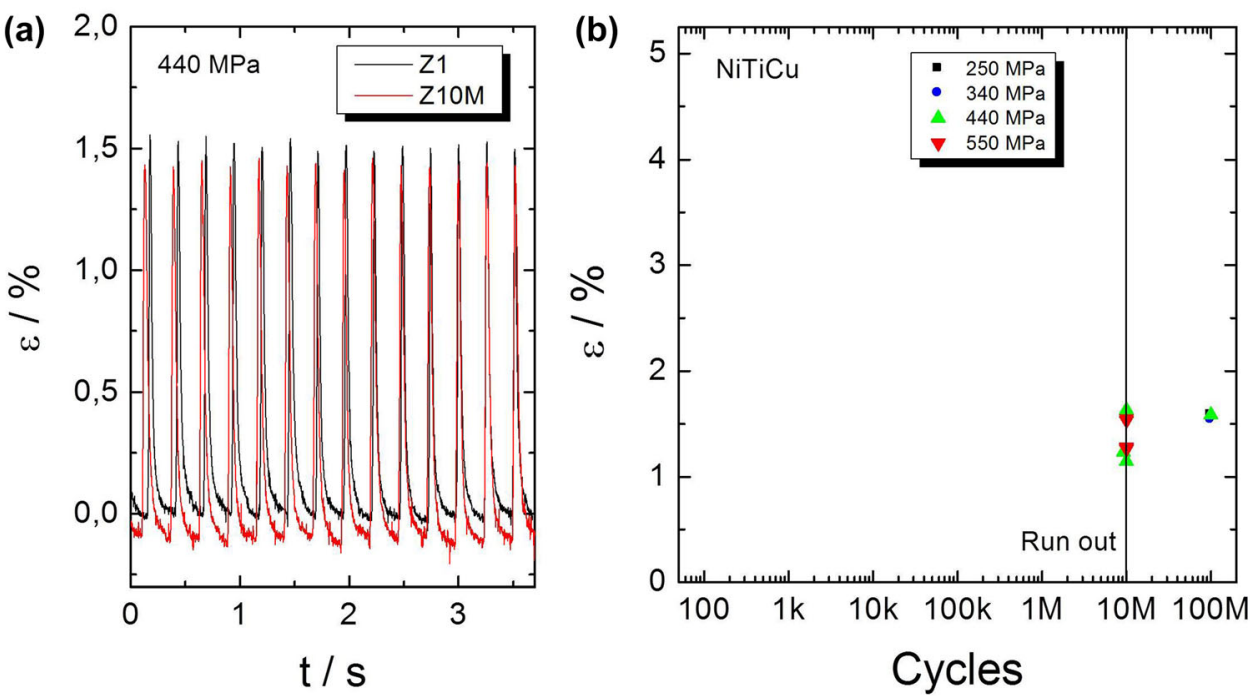

Table 1 Composition (at.\%) and transformation temperatures of sputtered $\mathrm{NiTi}, \mathrm{NiTiCu}$ and NiTiHf samples investigated in this study

\begin{tabular}{llllll}
\hline & $A_{\mathrm{s}}\left({ }^{\circ} \mathrm{C}\right)$ & $A_{\mathrm{f}}\left({ }^{\circ} \mathrm{C}\right)$ & $M_{\mathrm{s}}\left({ }^{\circ} \mathrm{C}\right)$ & $M_{\mathrm{f}}\left({ }^{\circ} \mathrm{C}\right)$ & $A_{\mathrm{f}}-M_{\mathrm{f}}(\mathrm{K})$ \\
\hline $\mathrm{Ni}_{46.3} \mathrm{Ti}_{53.7}$ & 55 & 76 & 45 & 30 & 46 \\
$\mathrm{Ni}_{33.2} \mathrm{Ti}_{54.2} \mathrm{Cu}_{12.6}$ & 64 & 67 & 53 & 48 & 19 \\
$\mathrm{Ni}_{49.2} \mathrm{Ti}_{31.4} \mathrm{Hf}_{19.3}$ & 191 & 217 & 123 & 115 & 102 \\
\hline
\end{tabular}

precipitates, which preferentially form at grain boundaries and the intersection of three grains, is confirmed by the SAED pattern. In contrast to $\mathrm{NiTiCu}$, binary Ti-rich NiTi shows significant microstructural changes after cycling. After $10 \mathrm{k}$ cycles (320 MPa, 3.0\% strain) an increase in dislocation density and an orientation toward stress 


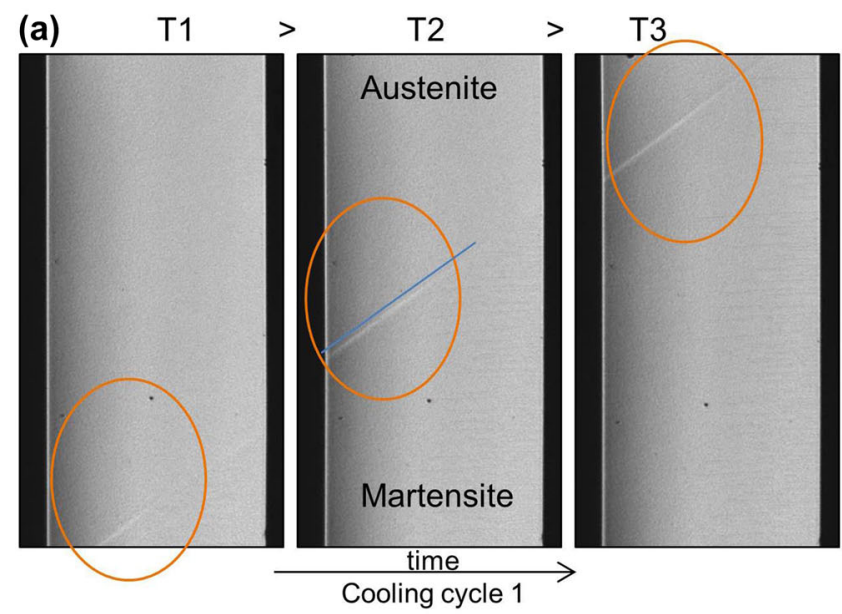

Fig. 4 Cooling sequence of a NiTiCu actuator stripe under constant pre-load. Polarization microscopy images show a distinct phase interface at the surface moving through the sample, increasing the

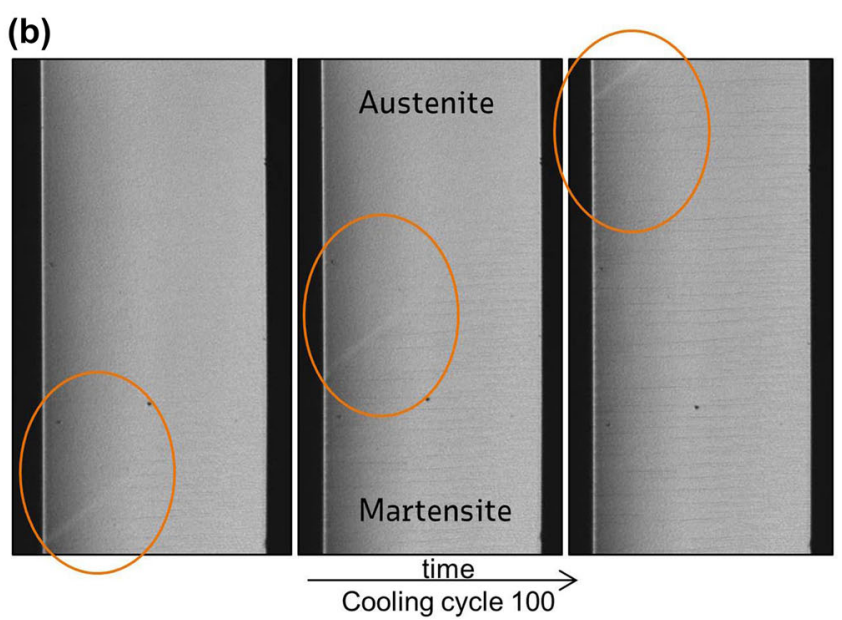

martensitic volume fraction during cooling. No change in transformation characteristics is observed between initial cycles, sequence (a), and after 100 thermal cycles, sequence (b)

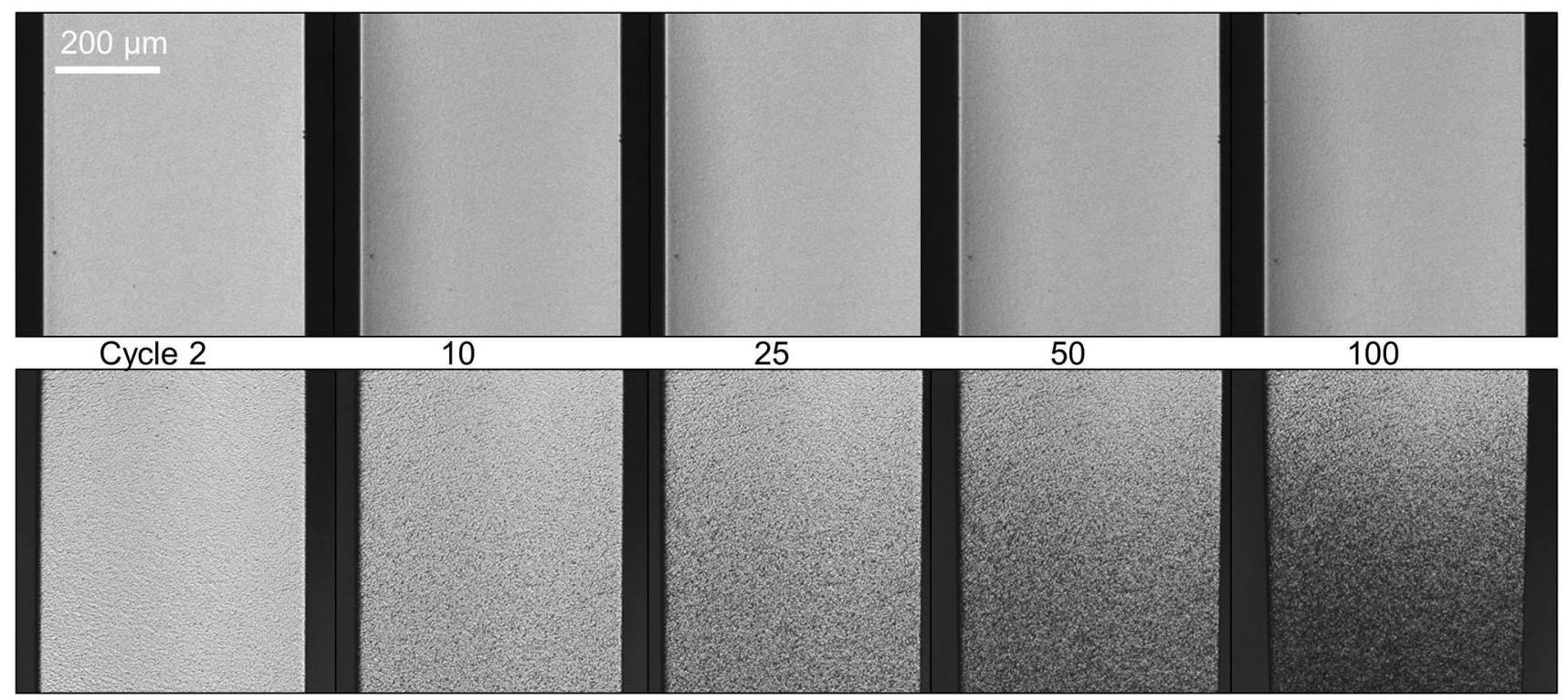

Fig. 5 Comparison of austenite surface roughness during thermal cycling. Whereas NiTiCu shows a smooth surface and no increase during cycling (top row), surface roughness of binary NiTi actuators increases significantly during cycling (bottom row)
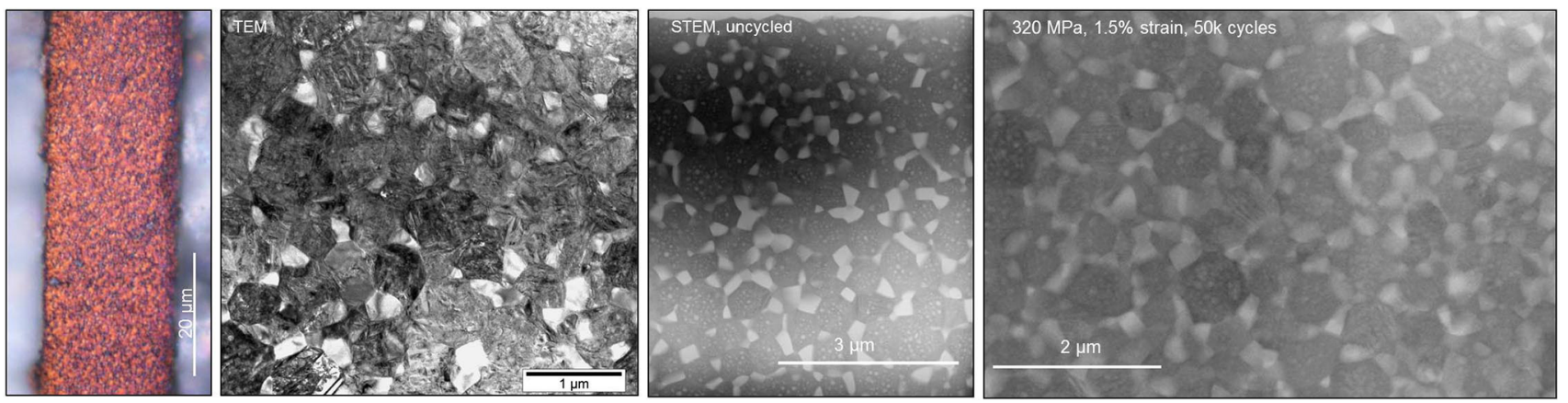

Fig. 6 Microstructure analysis of NiTiCu shows an average grain size of $600 \mathrm{~nm}$, with Ti2Ni precipitates at grain boundaries and intersections, and smaller intergranular globular sized $\mathrm{Ti}_{2} \mathrm{Ni}$ precipitates. After thermal cycling, no significant changes in the microstructure were observed 

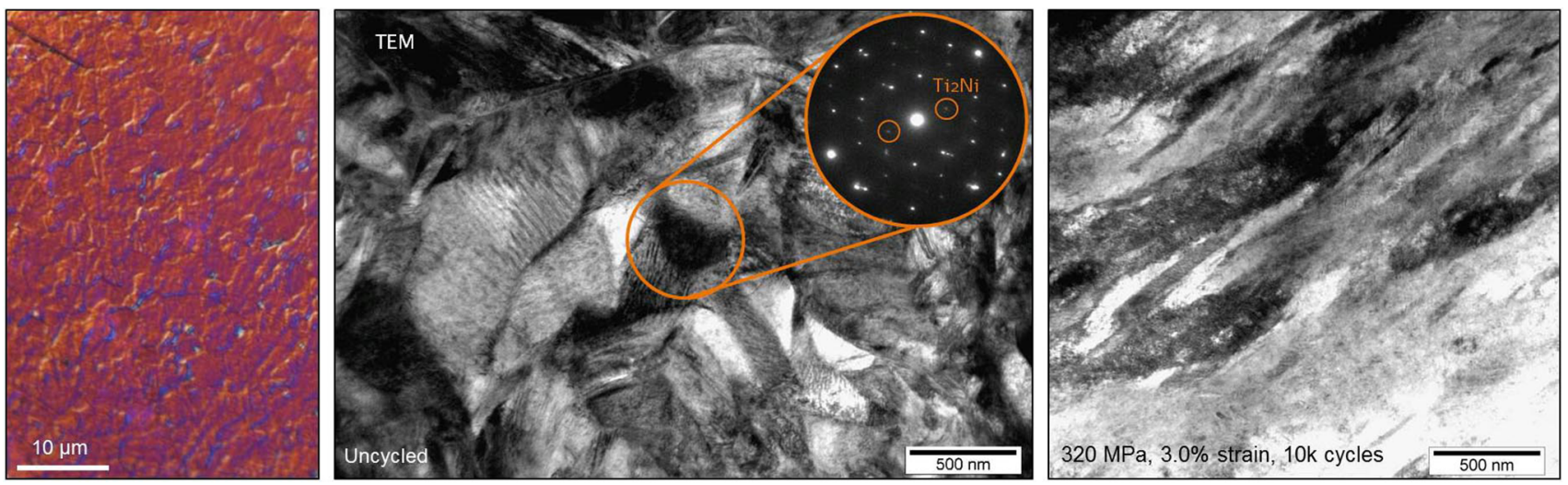

Fig. 7 Microstructure analysis of binary NiTi shows grain size of few $\mu \mathrm{m}, \mathrm{Ti}_{2} \mathrm{Ni}$ precipitates in the SAED pattern, and significant microstructural changes after thermal cycling, in contrast to $\mathrm{NiTiCu}$

direction is observed. A joint feature of both microstructures is the lack of inclusions in comparison to standard VIM/VAR or alternative VAR or VIM/VAR Nitinol [59]. This high material purity of sputtered NiTi based devices contributes significantly to an increase in fatigue life and fatigue safety limit [60], and increases corrosion resistance which is equally determined in particular by inclusions size [61].

\section{NiTiHf}

Freestanding NiTiHf actuators have been prepared by the same techniques as described above, Fig. 8a). The brittleness of NiTiHf reduced by increasing heating times; samples heat treated for $10 \mathrm{~min}$ showed earlier brittle fractures under load or bending compared to samples heat treated for 60 min or longer, while transformation temperatures were not significantly affected by the duration of the heat treatment. $A_{\mathrm{f}}$ transformation temperature increased from 210 up to $270{ }^{\circ} \mathrm{C}$ with the increase of the heat treatment temperature, while a hysteresis width of $\sim 100 \mathrm{~K}$ was found for all heat treatments, see Fig. 8b. For this study samples with a heat treatment resulting in an $M_{\mathrm{f}}$ temperature of $115{ }^{\circ} \mathrm{C}$ and an $A_{\mathrm{f}}$ of $215{ }^{\circ} \mathrm{C}$ were used, Fig. 8c.

The avg. grain size in the sputtered NiTiHf films after rapid crystallization is $\sim 100 \mathrm{~nm}$, see Fig. 9 . Due to the crystallization from an amorphous as deposited state without mechanical constraints and stress fields, grains grow in an isotropic fashion, as it is observed for all sputtered NiTi based films, inset of Fig. 9a. Small globular sized precipitates, appearing dark in the TEM bright field image, are found at grain boundaries. Several precipitates in the NiTiHf system exist that hinder phase transformation, e.g., $\mathrm{Ti}_{2} \mathrm{Ni}(\mathrm{Hf}), \mathrm{HfNi}(\mathrm{Ti}), \mathrm{Hf}_{2} \mathrm{Ni}(\mathrm{Ti})$, thus limiting the transformation region of the alloy to $\mathrm{Ni}$ contents $>40$ at. $\%$, and $\mathrm{Hf}$ contents $<30$ at.\% [25]. In Nirich NiTiHf alloys precipitates were found to play a crucial role to increase the material strength, and to obtain a near perfect dimensional stability during compression tests as well as a low thermal hysteresis [62]. Finely dispersed

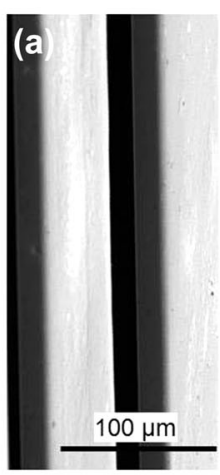

(b)

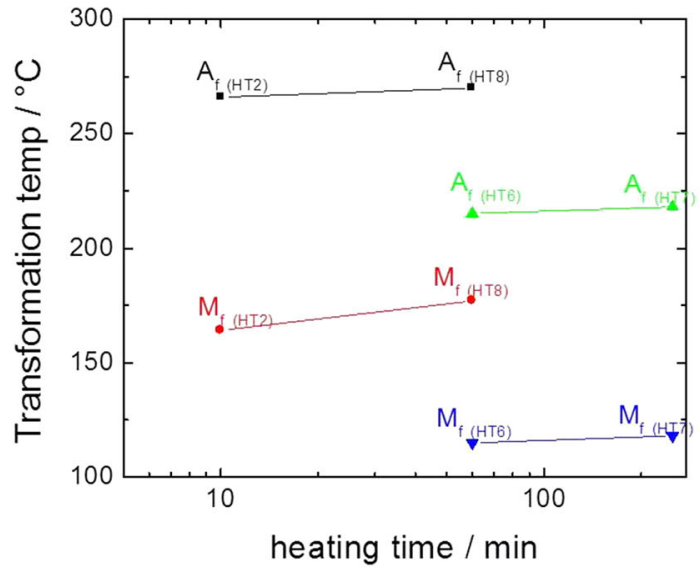

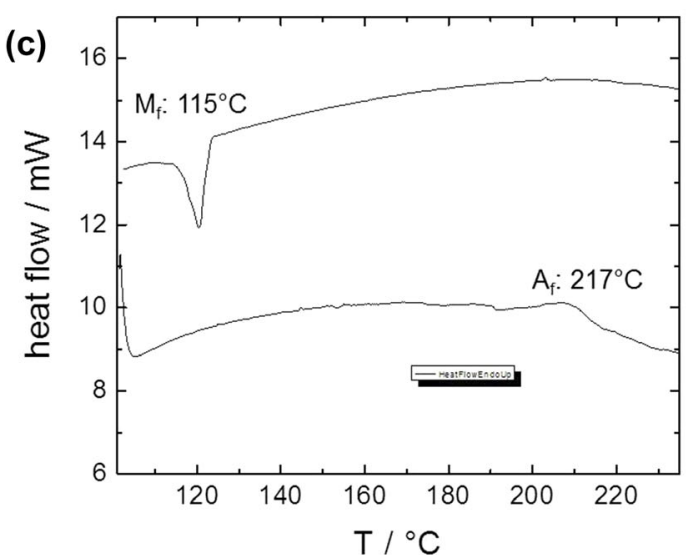

Fig. 8 a Sputtered NiTiHf stripes after heat treatment and surface finish. b Rather constant transformation temperatures for different heat treatment durations were obtained for different heat treatments. c DSC measurement of a sputtered NiTiHf film reveals a $100 \mathrm{~K}$ hysteresis width, and a $M_{\mathrm{f}}$ temperature of $115^{\circ} \mathrm{C}$ 


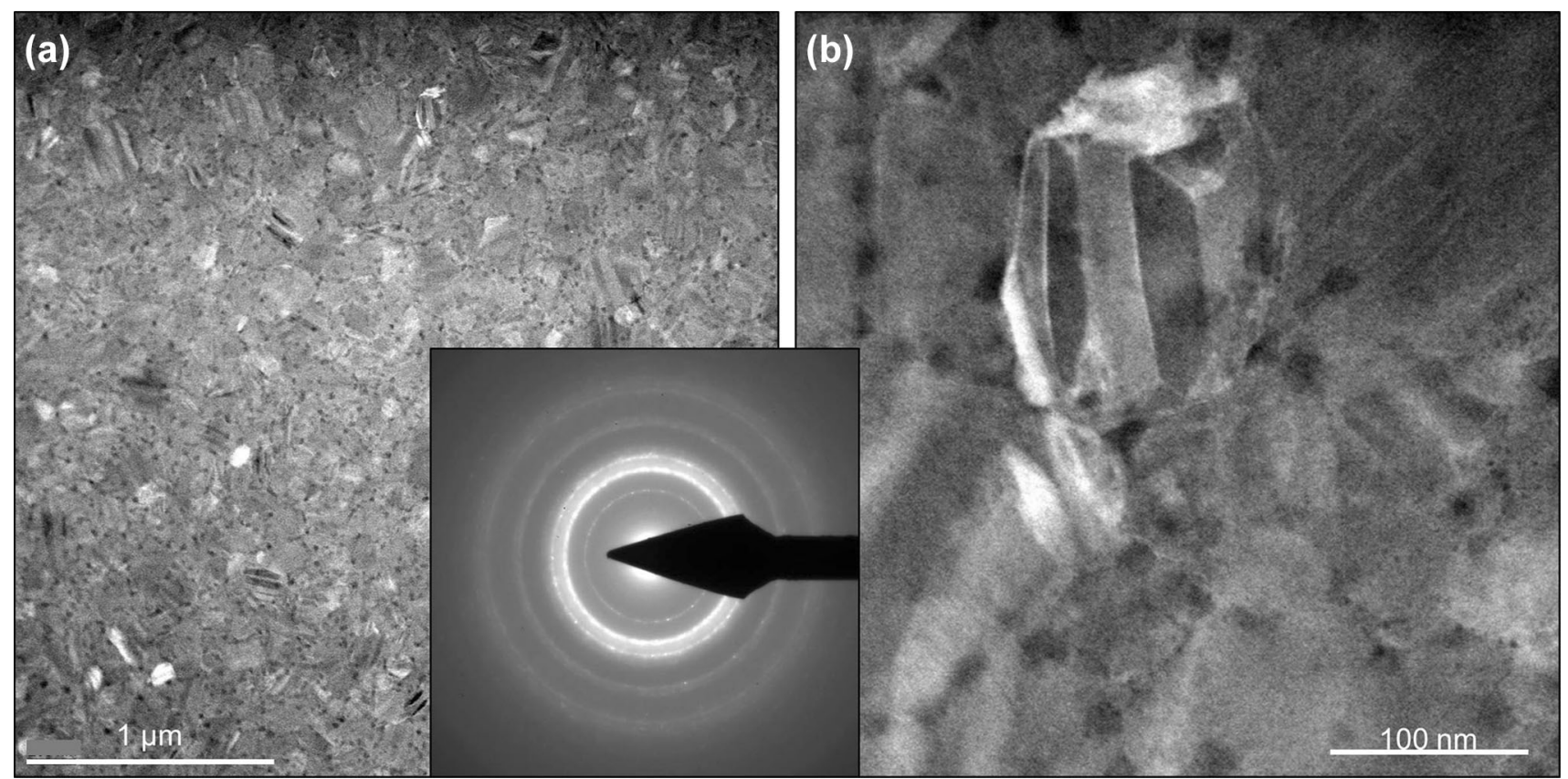

Fig. 9 TEM investigation of the NiTiHf films reveals an avg. grain size of $\sim 100 \mathrm{~nm}$ and an isotropic grain orientation typical for sputtered and stress-free crystallized $\mathrm{NiTi}$ based materials.

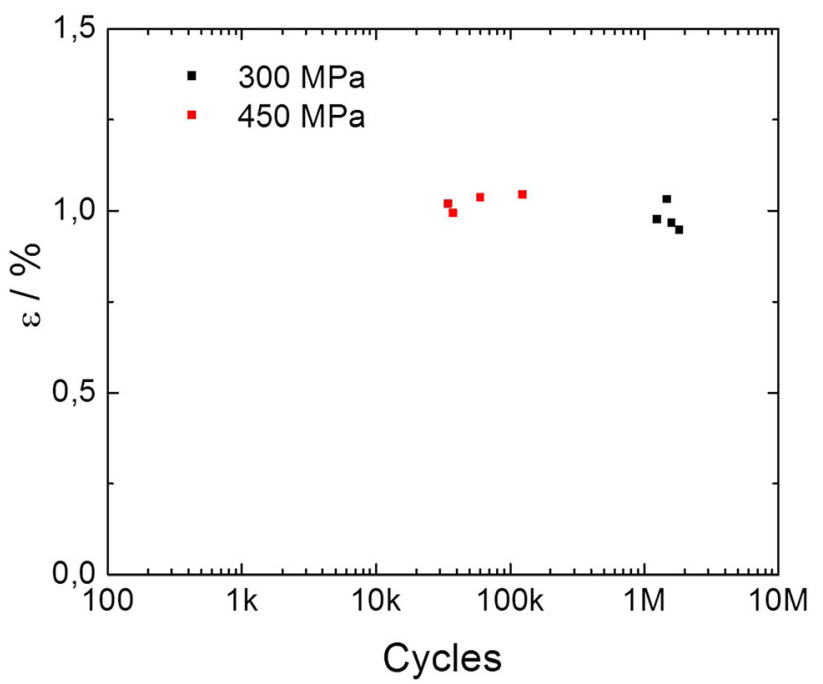

Fig. 10 Fatigue life of sputtered NiTiHf films under various loading conditions, tested in air at $\sim 1 \%$ strain. At $450 \mathrm{MPa}$ an average of $65 \mathrm{k}$ cycles were reached $\left(>1.510^{6}\right.$ cycles for $\left.300 \mathrm{MPa}\right)$

small precipitates are beneficial since they act as pinning sites against dislocation movement.

Due to the high transformation temperature of NiTiHf, high cycle fatigue tests were performed in air. When used in the tempered Silicone oil bath, the maximum voltage provided by the setup did not countervail the baths cooling capacity and the material did not reach its $A_{\mathrm{f}}$ temperature. Cooling times were hence increased to $350 \mathrm{~ms}$ to allow full
Precipitates (dark) are found preferably at grain boundaries, and martensitic variants are clearly visible within some grains

re-transformation to the martensitic state during cooling in air. Two parameter sets were tested, $1 \%$ strain at $300 \mathrm{MPa}$ and at $450 \mathrm{MPa}$, with 4 samples for each parameter set respectively. For $450 \mathrm{MPa}$, an average cycle number of $65 \mathrm{k}$ was reached, whereas for $300 \mathrm{MPa}$ pre-load, an average cycle number of $1.5 \times 10^{6}$ cycles was reached (Fig. 10), showing the high potential of NiTiHf thin film actuators. A significant increase in cycle number is expected if surface oxidation is avoided. In the described setup, cyclic heating to temperatures $\sim 215^{\circ} \mathrm{C}$ leads to $\mathrm{a} \sim 2 \mu \mathrm{m}$ thick thermal oxide layer after $1.5 \times 10^{6}$ cycles, analyzed by SEM. In order to avoid crack initiation at the surface, the formation of brittle surface layers should be prevented. Composition and heat treatment can further be adjusted to obtain microstructures with optimized properties. In particular a high thermal hysteresis is detrimental for the part's life time and energy efficiency. NiTiHf alloys however can show low hysteresis width in the range of a few tens of $\mathrm{K}$ [62], and operating temperatures $<200{ }^{\circ} \mathrm{C}$, which makes NiTiHf a promising material for various industries, such as automotive.

\section{Conclusion and Outlook}

This work characterizes NiTi based films with thicknesses of 20-25 $\mu \mathrm{m}$. Freestanding films from binary NiTi, ternary $\mathrm{NiTiCu}$, and NiTiHf were fabricated by DC magnetron sputtering and their properties were investigated. $\mathrm{NiTiCu}$ 
shows an excellent fatigue life: all $\mathrm{NiTiCu}$ samples tested reached the $10^{7}$ cycles test run out and cycle numbers $>10^{8}$ are possible. Strains of up to $1.5 \%$ and stresses up to $550 \mathrm{MPa}$ were tested. The high cyclic stability is a result of the good phase reversibility and crystallographic compatibility between austenite and martensite in NiTiCu, paired with a high material purity. NiTiHf films showed life times of $>1.5 \times 10^{6}$ cycles at certain test conditions (1\% strain, $300 \mathrm{MPa}$ ), but obviously testing conditions were more demanding in terms of the significantly higher temperature interval during cycling and a higher maximum temperature resulting in surface oxidation of NiTiHf actuators tested in air. Higher cycle numbers can be achieved if hysteresis and $A_{\mathrm{f}}$ temperature are reduced. The potential of highly precise and highly pure $\mathrm{NiTiCu}$ and NiTiHf structures from sputtered film for high cycle microactuator applications is demonstrated.

Acknowledgements We acknowledge the contribution of O. Rothe (design, development, and implementation of the fatigue testing setup), Prof. J. McCord (providing polarization microscopy equipment for optical surface investigations), Dr. Ulrich Schürmann, and Prof. Lorenz Kienle for TEM investigations.

\section{References}

1. Ishida S, Takei M (1995) Effect of heat treatment on shape memory behavior of Ti-rich Ti-Ni thin films. Mater Trans JIM 36(11):1349-1355

2. Krulevitch L, Ramsey T, Hamilton N (1996) Thin film shape memory alloy microactuators. J Microelectromech Syst 5(4):270

3. Ishida S, Takei N, Miyazaki H (1996) Effect of aging on shape memory behavior of Ti-51.3 at.\% Ni thin films. Metall Mater Trans A 27(12):3753

4. Miyazaki H, Ishida S (1996) Martensitic transformations in sputter-deposited $\mathrm{Ti}-\mathrm{Ni}-\mathrm{Cu}$ shape memory alloy thin films. Thin Sol Films 281-282:364

5. Quandt H, Holleck FT (1996) Kohl: Sputter deposition of TiNi, TiNiPd and TiPd films displaying the two-way shape-memory effect. Sens Actuators A 53(1-3):434-439

6. Miyazaki N, Ishida K (1997) Recent developments in sputterdeposited Ti-Ni-base shape memory alloy thin films. J Phys IV 07, C5-275-C5-280

7. de Miranda RL, Zamponi C, Quandt E (2013) Micropatterned freestanding superelastic TiNi films. Adv Eng Mater 15(1-2):66

8. Bechtold C, de Miranda RL, Quandt E (2015) Capability of sputtered micro-patterned NiTi thick films. Shap Mem Superelast. https://doi.org/10.1007/s40830-015-0029-9

9. Loger E, Haupt, de Miranda RL, Lutter Q (2016) Microstructured nickel-titanium thin film leaflets for hybrid tissue engineered heart valves fabricated by magnetron sputter deposition. Cardiovasc Eng Technol 7:69

10. Levi K, Carman GP (2008) Smart materials applications for pediatric cardiovascular devices. Pediatr Res 63:552

11. Bechtold C, de Miranda RL, Chluba C, Quandt E (2016) Method for fabricating miniaturized $\mathrm{NiTi}$ self-expandable thin film devices with increased radiopacity. Shap Mem Superelast 2:391

12. Bechtold C, de Miranda RL, Chluba C, Quandt E (2016) Fabrication of self-expandable NiTi thin film devices with micro- electrode array for bioelectric sensing, stimulation and ablation. Biomed Microdev 18:106

13. Miyazaki I (1999) Martensitic transformation and shape memory behavior in sputter-deposited TiNi-base thin films. Mater Sci Eng A 273-275:106-133

14. Ishida S, Kimura T, Miyazaki S (2000) Stress-strain curves of sputter-deposited Ti-Ni thin films. Philos Mag A 80(4):967-980

15. Matsunaga T, Kajiwara S, Ogawa K, Kikuchi T, Miyazaki S (1999) High strength Ti_Ni-based shape memory thin films. Mater Sci Eng A 273:745

16. Sato M, Ishida A, Miyazaki S (1998) Two-way shape memory effect of sputter-deposited thin films of Ti 51.3 at.\% Ni. Thin Solid Films 315:305

17. Ishida A, Sato M, Kimura T, Sawaguchi T (2001) Effects of composition and annealing on shape memory behavior of Ti-rich Ti-Ni thin films formed by sputtering. Mater Trans 42(6):1060

18. Zhang JX, Sato M, Ishida A (2006) Deformation mechanism of martensite in Ti-rich Ti-Ni shape memory alloy thin films. Acta Mater 54(4):1185

19. Meng XL, Sato M, Ishida A (2008) Structure of martensite in Tirich $\mathrm{Ti}-\mathrm{Ni}-\mathrm{Cu}$ thin films annealed at different temperatures. Acta Mater 56(14):3394

20. Ishida A, Sato M, Gao Z (2013) Properties and applications of $\mathrm{Ti}-\mathrm{Ni}-\mathrm{Cu}$ shape-memory-alloy thin films. J Alloys Compd 577(S1):S184

21. Ishida A, Sato M, Gao Z (2014) Effects of Ti content on microstructure and shape memory behavior of Tix$\mathrm{Ni}(84.5-\mathrm{x}) \mathrm{Cu} 15.5(\mathrm{x}=44.6-55.4)$ thin films. Acta Mater 69:292

22. Ishida A, Sato M, Gao Z (2015) Microstructure and shape memory behavior of Ti55.5Ni44.5_xCux $\left(x=11.8 \_23.5\right)$ thin films. Intermetallics 58:103

23. Grummon DS (2003) Thin-film shape-memory materials for high-temperature applications. JOM 55:24

24. Rao J, Lawson K, Nicholls JR (2010) Nickel titanium and nickel titanium hafnium shape memory alloy thin films. Surf Sci Coat 204:2331

25. König D, Zarnetta R, Savan A, Brunken H, Ludwig A (2011) Phase transformation, structural and functional fatigue properties of Ti-Ni-Hf shape memory thin films. Acta Mater 59(8):3267

26. Sawaguchi T, Sato M, Ishida A (2001) Ti-Pd-Ni high temperature shape memory thin films formed with carousel type magnetron sputtering apparatus. J Phys IV 11:Pr8-427-Pr8-432

27. Mohanchandra KP, Shin D, Carman GP (2005) Deposition and characterization of Ti-Ni-Pd and Ti-Ni-Pt shape memory alloy thin films. Smart Mater Struct 14(5):21

28. Zhang C, Yang C, Ding D, Qian S, Wu J (2005) Characteristics of Ti-Ni-Pd shape memory alloy thin films. Mater Charact 55:340-344

29. Zarnetta R, Zelaya E, Eggeler G, Ludwig A (2009) Influence of precipitates on the thermal hysteresis of Ti-Ni-Pd shape memory thin films. Scr Mater 60(5):352

30. Kim HY, Yuan Y, Nam T, Miyazaki S (2011) Effect of Pd content on crystallization and shape memory properties of $\mathrm{Ti}-\mathrm{Ni}-$ Pd thin films. Int J Smart Nano Mater 2(1):9

31. Evirgen A, Pons J, Karaman I, Santamarta R, Noebe RD (2018) $\mathrm{H}$-Phase precipitation and martensitic transformation in Ni-rich $\mathrm{Ni}-\mathrm{Ti}-\mathrm{Hf}$ and $\mathrm{Ni}-\mathrm{Ti}-\mathrm{Zr}$ high-temperature shape memory alloys. Shap Mem Superelast 4(1):85

32. Cui J, Chu YS, Famodu OO, Furuya Y, Hattrick-Simpers J, James RD, Ludwig A, Thienhaus A, Wuttig M, Zhang Z, Takeuchi I (2006) Combinatorial search of thermoelastic shape-memory alloys with extremely small hysteresis width. Nat Mater 5:286

33. Grossmann Ch, Frenzel J, Sampath V, Depka T, Eggeler G (2009) Elementary transformation and deformation processes and the cyclic stability of NiTi and $\mathrm{NiTiCu}$ shape memory spring actuators. Metall Mater Trans A 40A(11):2530 
34. Bechtold C, Chluba C, de Miranda RL, Quandt E (2012) High cyclic stability of the elastocaloric effect in sputtered $\mathrm{TiNiCu}$ shape memory films. Appl Phys Lett 101:091903

35. Chluba C, Ge W, de Miranda RL, Strobel J, Kienle L, Quandt E, Wuttig M (2015) Ultralow-fatigue shape memory alloy films. Science 348:1004

36. Chluba C, Ge W, Dankwort T, Bechtold C, de Miranda RL, Kienle L, Wuttig M, Quandt E (2016) Effect of crystallographic compatibility and grain size on the functional fatigue of sputtered TiNiCuCo thin films. Philos Trans R Soc A 374:20150311

37. Sehitoglu H, Wu Y, Patriarca L, Ojha A, Zhang S, Chlumlyakov Y, Nishida M (2017) Superelasticity and shape memory behavior of NiTiHf alloys. Shap Mem Superelast 3:168

38. Sehitoglu H, Wu Y, Patriarca L (2017) Shape memory functionality under multi-cycles in NiTiHf. Scr Mater 129:11

39. Kohl M, Dittmann D, Quandt E, Winzek B (2000) Thin film shape memory microvalves with adjustable operation temperature. Sens Actuators A 83:214

40. Büttgenback S, Bütefisch S, Leester-Schädel M, Wogersien A (2001) Shape memory microactuators. Microsyst Technol 7:165

41. Xu D, Wang L, Ding G, Zhou YH, Yu A, Cai B (2001) Characteristics and fabrication of NiTi-Si diaphragm micropump. Sens Actuators A 93:87

42. Gill JH, Chang DT, Momoda LA, Carman GP (2001) Manufacturing issues of thin film NiTi microwrapper. Sens Actuators A 93:148

43. Gill JJ, Ho K, Carman GP (2002) Three-dimensional thin-film shape memory alloy microactuator with two-way effect. J Microelectromech Syst 11(1):68

44. Kohl M (2004) Shape memory microactuators. Springer, Berlin

45. Seong M, Mohanchandra KP, Lin Y, Carman GP (2008) Development of a 'bi-layer lift-off' method for high flow rate and high frequency Nitinol MEMS valve fabrication. J Micromech Microeng 18(7):075034

46. Barth J, Krevet B, Kohl M (2009) A bistable SMA microactuator with large work output. Transducers M3P(005):41

47. Megnin C, Barth J, Kohl M (2011) A bistable SMA microvalve for 3-2-way control. Sens Actuators A 188:285

48. Megnin C, Kohl M (2014) Shape memory alloy microvalves for a fluidic control system. J Micromech Microeng 24:025001

49. Brinson LA, Schmidt I, Lammering R (2004) Stress-induced transformation behavior of a polycrystalline NiTi shape memory alloy: micro and macromechanical investigations via in situ optical microscopy. J Mech Phys Solids 52:1549-1571

50. ASTM E3097-17 Standard test method for mechanical uniaxial constant force thermal cycling of shape memory alloys

51. Shaw K (1997) On the nucleation and propagation of phase transformation fronts in a NiTi alloy. Acta Mater 45(2):683

52. Tan L, Sittner S (2004) Lüders-like deformation associated with stress-induced martensitic transformation in NiTi. Scr Mater 50(2): 193

53. Zheng L (2016) He, Yj, Moumni, Z: Luders-like band front motion and fatigue life of pseudoelastic polycrystalline NiTi shape memory alloy. Scr Mater 123:46

54. Gil FJ, Manero JM, Planell JA (1995) Effect of grain size on the martensitic transformation in NiTi alloy. J Mater Sci 30(10):2526

55. Yin H, Moumni S (2016) Effects of grain size on tensile fatigue life of nanostructured NiTi shape memory alloy. Int J Fatigue $88: 166$

56. Kockar K, Kim C, Sharp Y (2008) Thermomechanical cyclic response of an ultrafine-grained NiTi shape memory alloy. Acta Mater 56(14):3630

57. Ishida $\mathrm{S}$ (2011) Shape memory behaviour of Ti51.5Ni(48.5-x)Cu $(x=23.4-37.3)$ thin films with submicron grain sizes. Intermetallics 19(12):1878-1886

58. Frenzel J, Burow JA, Payton E, Rezanka S, Eggeler G (2011) Improvement of $\mathrm{NiTi}$ shape memory actuator performance through ultra-fine grained and nanocrystalline microstructures. Adv Eng Mater 13(4):256

59. Wohlschlögel M, de Miranda RL, Schüßler A, Quandt E (2016) Nitinol: tubing versus sputtered film: microcleanliness and corrosion behavior. J Biomed Mater Res 104(6):1176

60. Siekmeyer G, Schüßler A, Quandt E (2014) Comparison of the fatigue performance of commercially produced nitinol samples versus sputter-deposited nitinol. JMEPEG 23:2437

61. Wohlschlögel M, Steegmüller R, Schüßler A (2014) Effect of inclusion size and distribution on the corrosion behavior of medical-device grade nitinol tubing. J Mater Eng Perf 23(7):635

62. Saghaian SM, Karaca HE, Souri M, Turabi AS, Noebe RD (2016) Tensile shape memory behavior of Ni50.3Ti29.7Hf20 high temperature shape memory alloys. Mater Des 101:340

Publisher's Note Springer Nature remains neutral with regard to jurisdictional claims in published maps and institutional affiliations. 